\title{
O GARIMPO BOM FUTURO COMO FERRAMENTA PARA O ENSINO DE QUÍMICA E DA EDUCAÇÃO AMBIENTAL.
}

\author{
Renato André Zan ${ }^{1}$, Filomena Maria Minetto Brondani ${ }^{2}$, Nathalia Vieira Barbosa ${ }^{3}$, Dionatas \\ Ulises de Oliveira Meneguetti ${ }^{4}$, Irizádina Maria da Silva ${ }^{5}$, Franciele Militino Bissol6
}

\footnotetext{
${ }^{1}$ Mestre em Química - Docente e Coordenador do Curso de Especialização de Educação em Ciências e Matemática da Faculdade de Educação e Meio Ambiente - FAEMA - Ariquemes - Rondônia - Avenida Machadinho, 4349, Setor 06, CEP: 76870-293- Ariquemes - Rondônia. renato-zan@hotmail.com

${ }^{2}$ Mestre em Biologia Experimental - Docente e Coordenadora do Curso de Licenciatura em Química da Faculdade de Educação e Meio Ambiente - FAEMA.

${ }^{3}$ Mestre em Química - Docente do Curso de Licenciatura em Química da Faculdade de Educação e Meio Ambiente FAEMA.

4Mestre em Genética e Toxicologia Aplicada - Docente e Coordenador de Extensão da Faculdade de Educação e Meio Ambiente - FAEMA.

5Graduada em Licenciatura em Química - Faculdade de Educação e Meio Ambiente - FAEMA.
}

\section{RESUMO}

O garimpo Bom Futuro é denominado o maior garimpo a céu aberto do mundo, foi descoberto no ano de 1987 e a partir dessa descoberta começou a garimpagem da sua maior riqueza que é a Cassiterita $\left(\mathrm{SnO}_{2}\right)$, que contém cerca de $66 \%$ a $75 \%$ de Estanho, e é passada por um processo de beneficiamento, do qual retira-se um Estanho com 99,98\% de pureza. Este minério é usado para diversas finalidades como, folha-de-flandres e ligas metálicas como solda, bronze, liga de pewter e em compostos químicos. O estanho ajudou e continua ajudando na economia do Estado de Rondônia, sendo cada vez mais utilizado no nosso dia-a-dia, sabendo-se de tamanho potencial de estudo, este trabalho tem por finalidade propor a visita do garimpo como ferramenta no ensino de educação ambiental e química, dando um olhar diferenciado a um garimpo e mostrar o grande potencial do garimpo como um grande laboratório a céu aberto.

Palavras-chave: Cassiterita, estanho e garimpo.

\section{ABSTRACT}

Bom Futuro mining is called the largest open pit gold mining in the world, was discovered in 1987 and from this discovery began with the digging of its greatest wealth is cassiterite $\left(\mathrm{SnO}_{2}\right)$, which contains about $66 \%$ to $75 \%$ tin, and is passed through a beneficiation process, which leaves her with a tin of $99.98 \%$ purity. This ore is used in various purposes such as, tin and alloys as solder, brass, pewter alloy and chemical compounds. The tin helped and continues to help the economy of the state of Rondonia, being increasingly used in our day to day, knowing the potential size of the study, this paper aims to propose a visit from mining as a tool in teaching environmental education and chemistry, giving a different look to a gold mining and show the great potential of 
mining as a major laboratory in the open.

Keywords: Cassiterite, tin e tin mining.

\section{INTRODUÇÃO}

O garimpo Bom Futuro tem uma grande importância histórica para o estado de Rondônia e para o município de Ariquemes, no qual está localizado. Com a sua descoberta no ano de 1987 a maioria dos agricultores, madeireiros e comerciantes trocaram suas atividades pelas do garimpo, razão pela qual fez existir no Bom Futuro mais de 15.000 garimpeiros (RONALTTI, 2008).

Ariquemes é um dos 52 municípios do Estado de Rondônia, localizado em $63^{\circ} 02^{\prime 2} 7^{\prime \prime}$ longitude oeste e $09^{\circ} 54^{\prime} 48^{\prime \prime}$ latitude Sul, apresentando altitude de $148 \mathrm{~m}$ em referência ao nível do mar, com um total de $4.706,70 \mathrm{~km}^{2}$ de área territorial, sendo $64 \mathrm{~km}^{2}$ de área urbana. (PREFEITURA, 2011). Segundo o Censo 2010 do Instituto Brasileiro de Geografia e Estatística (IBGE, 2010), Ariquemes possui 90.353 habitantes, sendo 45.543 homens e 44.810 mulheres.

O garimpo é de fundamental importância para economia do estado. No começo a retirada de Cassiterita no garimpo Bom Futuro ajudou a levar o Brasil ao maior produtor mundial de estanho, hoje em dia não está em primeiro lugar na produção, mas o estanho retirado do garimpo Bom Futuro ainda é uma grande fonte de riqueza para o Estado. (DARLENE, 2001).

Tendo o conhecimento da grande importância do Garimpo Bom Futuro para região de Ariquemes e para o estado de Rondônia, este trabalho vem ao encontro da necessidade de apresentar novas maneiras e ambientes de aprendizagem do ensino de química e da educação ambiental, quebrando barreiras e conceitos errôneos de como se passar o conhecimento da química. Segundo Chassot 1995, sugere-se que deve-se ensinar química para permitir que o cidadão possa interagir melhor com o mundo, preparando-o para a vida, para o trabalho e para o lazer. O trabalho tem por objetivo demonstrar como o Garimpo Bom Futuro pode ser utilizado como ferramenta de educação para o ensino de química e da educação ambiental.

\section{ESTRATÉGIA METODOLÓGICA}

Foi realizada no dia 16/04/2011 uma visita ao Grimpo Bom Futuro que contou com a participação de 40 acadêmicos do curso de licenciatura em química licenciatura da Faculdade de Educação e Meio Ambiente - FAEMA - de Ariquemes- RO.

Um curso de licenciatura em química como formador de professores tem por obrigação e responsabilidade adicionar à sua grade curricular de disciplinas a dimensão ambiental contextualizada como forma de dar suporte a formação de um educador preparado a usar as ferramentas da contextualização do seu ambiente de ensino. Muitos conteúdos químicos propiciam a contextualização, desenvolvendo a capacidade de participação e tomada de decisão com os debates em sala de aula e pela problematização de situações em que o aluno tenha que propor soluções. O presente trabalho tem como laboratório de aprendizagem o garimpo Bom Futuro, onde a prática proposta motiva a participação acadêmica e possibilita o trabalho em grupo, a comunicação e a defesa/argumentação de idéias, tornando as aulas mais dinâmicas e favorecendo a articulação ensino/aprendizagem, atendendo, assim, às exigências dos Parâmetros 
Curriculares Nacionais (PCN) de química do Ministério da Educação (BRASIL, 2000). Este trabalho também se baseia na metodologia da problematização, onde problematizar um tema é relacionar com outros temas que geraram etapas que irá requerer dinâmica ao elaborar, partindo da observação da realidade, teorizando de forma a trazer para o cotidiano, levando a prática, elaborando um possível diagnóstico que em sua aplicação, a prática poderá gerar uma mudança.

A dinâmica da aula proposta foi a visita ao garimpo e observação de todos os processos de extração da cassiterita, seus impactos ao meio ambiente e também a observação de todo o processo de extração do estanho presente na cassiterita e dos resíduos que sobram do processo de separação do mesmo.

\section{Mineração da cassiterita no garimpo}

O Bom Futuro foi descoberto por seringueiros e madeireiros que retiravam madeira perto do Rio Santa Cruz, o que atraiu vários homens para trabalharem como garimpeiros. Nessa época não havia delimitação de espaço para garimpagem, cada um marcava sua parte do garimpo por conta própria, ocorrendo várias brigas e mortes, durante os conflitos (BRASIL, 2009).

A empresa MS Mineradora LTDA, requereu a área por meios legais determinadas pelos órgãos competentes, porém os garimpeiros não cumpriram a determinação, foi a partir de então que o Departamento Nacional de Produção Mineral (DNPM) criou a portaria 226 de 19 de setembro de 1988, que determinava que toda produção de cassiterita fosse comercializada pela requerente MS Mineração LTDA, e mesmo assim os produtores de cassiterita não aceitaram a portaria e continuaram o comércio ilegal, fazendo com que as empresas de mineração reduzissem as operações porque não conseguiam competir com os custos de produção inferiores do garimpo (CUTTER, 2005).

As grandes empresas, temendo um crescimento vertiginoso da produção garimpeira e queda de preço da cassiterita, pressionaram o governo a proibir os garimpeiros. Então o governo proíbe a garimpagem de $\mathrm{SnO}_{2}$ mas, ainda assim continuou havendo ilegalidade, porém esses que estavam trabalhando ilegalmente ficaram sendo perseguidos pelo governo Federal (DALL'IGNA, 1996).

Em seguida a lavra foi concedida a Empresa Brasileira de Estanho S/A (Ebesa), que começou a organizar a extração, e no ano de 1988 adicionou 49\% na produção e em 1989 mais $29 \%$, chegando o Brasil a sua máxima produção, cerca de 54.700 toneladas de estanho contido em cassiterita. O minério de fácil extração e de alto teor foi ficando escasso no garimpo, por causa disso a partir de 1990 a sua produção entrou em declínio, além do preço no mercado internacional que estavam baixos, diminuindo ainda mais a produção brasileira (BRASIL, 2009).

Nos dias atuais a mineração continua ajudando na economia do estado de Rondônia, não está em alta como no ano de 1988, porém o valor do estanho melhorou, a crise passou e as mineradoras estão exportando um estanho e alta qualidade e ele está custando em média 14.000 dólares a tonelada, após o rígido processo de beneficiamento onde restam $99,98 \%$ de estanho puro (DALL'IGNA, 1996). 


\section{Localização e acesso}

O garimpo Bom Futuro (Figura 1) está localizado nos municípios de Ariquemes e Alto Paraíso, na área denominada Igarapé Santa Cruz. O acesso é feito pela rodovia RO-459 em direção a Alto Paraíso, percorrendo $34 \mathrm{~km}$ até a entrada.

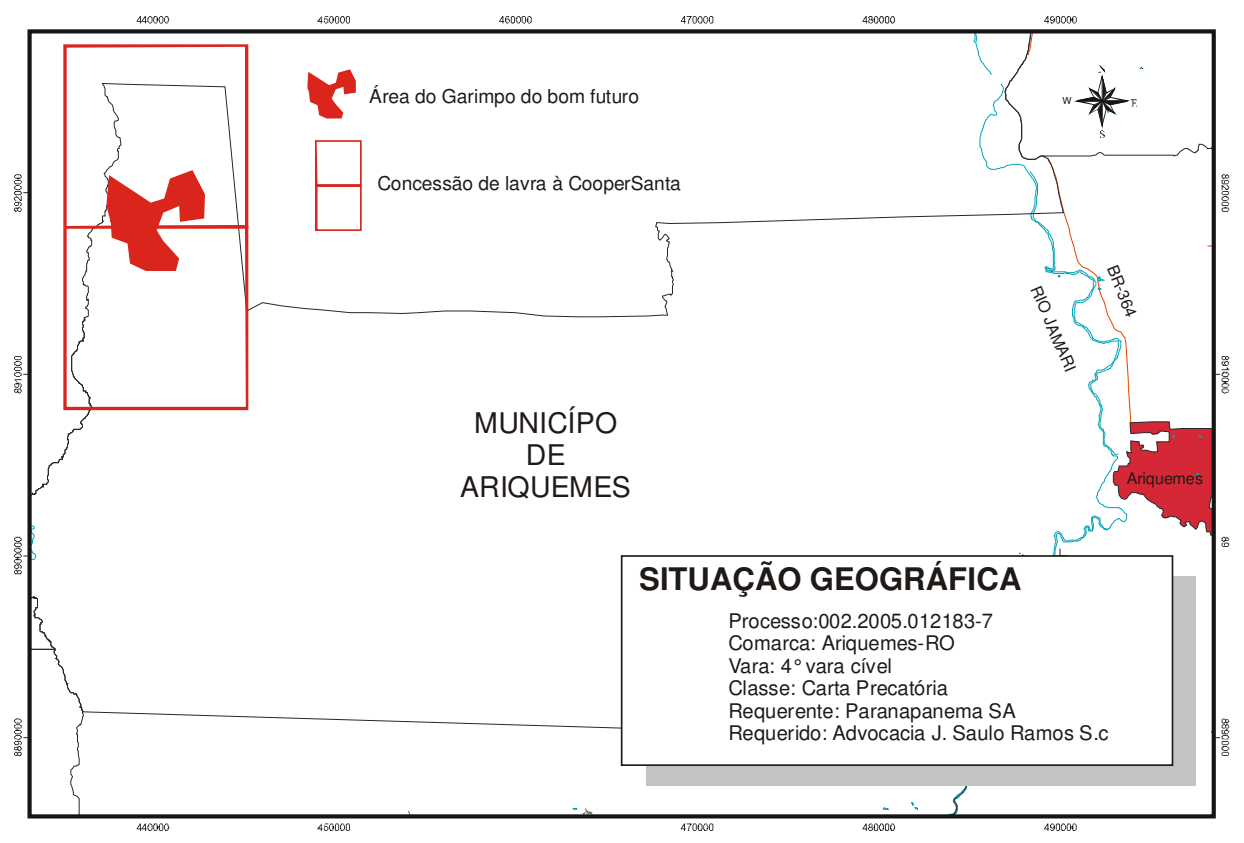

Figura 1. Situação geográfica da região, localização e acesso do garimpo Bom Futuro.

\section{Hidrografia}

O garimpo Bom Futuro é constituído dos igarapés Jacaré, Mutum e Santa Cruz, que são afluentes do rio Candeias, e da serrota do Bom Futuro (PORSANI, 2004).

\section{Geologia}

O garimpo Bom Futuro é formado por duas colinas isoladas numa região plana, denominadas bom futuro e palanqueta. $\mathrm{O}$ Bom futuro constitui um relevo residual com $100 \mathrm{~m}$ de desnível em forma de bumerangue onde a cassiterita é intensamente explorada, a estrutura compreende dois centros subvulcânicos encaixados gnaisses e em anfibolitos. A Palanqueta possui uma forma semicircular, e é composta de três fácies graníticas: granito porfíritico, granito fino e albita granito, aos quais são associados corpos de greisens (RAMOS, 2003). 


\section{Impactos ambientais}

Os impactos ambientais na região do Bom Futuro devido ao garimpo foram gigantescos: mais de 800 mil metros cúbicos de resíduos da exploração da cassiterita eram lançados por mês nos igarapés e rios adjacentes, o sistema fluvial da região foi comprometido num raio de mais de $200 \mathrm{~km}$, o assoreamento dos rios impedia a penetração da luz solar nas águas, dificultando a fotossíntese e gerando uma série de desequilíbrios na vida aquática, ocorreram alterações significativas na concentração de oxigênio e nutrientes, principalmente nitrogênio e fósforo (BRASIL, 2004).

Houve também uma mudança na flora e na fauna da região, muitas espécies de árvores como o Breu-Branco e o Açari foram completamente extintas. Na Figura 2 pode-se observar o impacto que o garimpo causa ao meio ambiente (LONGO; RIBEIRO; MELO, 2005).

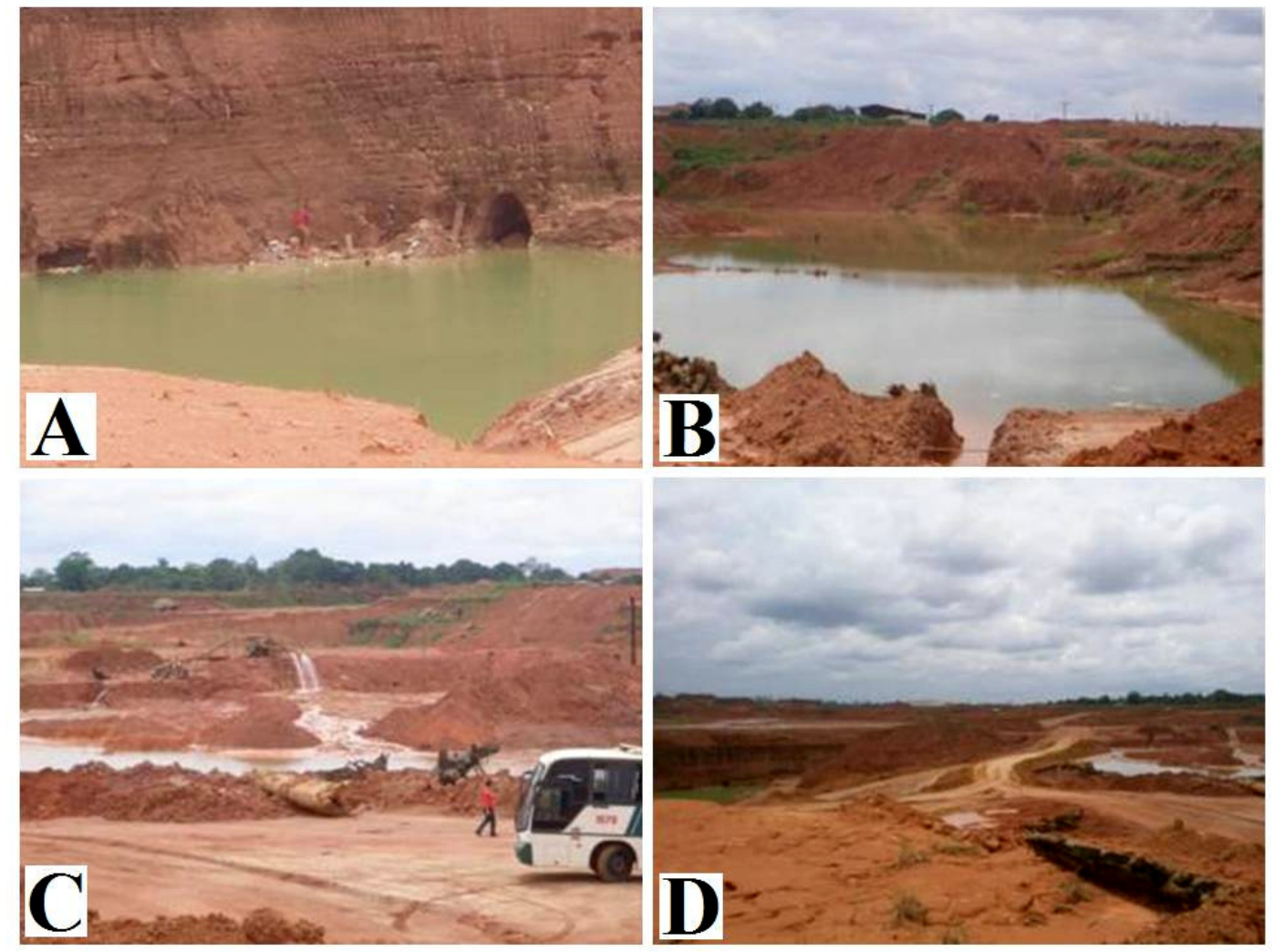

Figura 2. A, B, C e D são imagens dos impactos ambientais causados pela mineração em diversos pontos do garimpo Bom Futuro. (Imagens: dos próprios autores)

\section{Cassiterita $\left(\mathrm{SnO}_{2}\right)$}

O principal minério de estanho é a cassiterita que é um dióxido de estanho, de fórmula $\mathrm{SnO}_{2}$. A cassiterita forma cristais tetragonais e tem dureza 6 a 7 na Escala de Mohs, com densidade relativa de 7 . Normalmente este minério tem coloração marrom escura ou negra, além de ser opaco. Ocorre em veios submetidos à alta temperatura, ou associado à pegmatitas, um tipo de 
rocha ígnea. A cassiterita (Figura 3) é o único mineral de estanho de importância econômica (RODRIGUES, 2001).

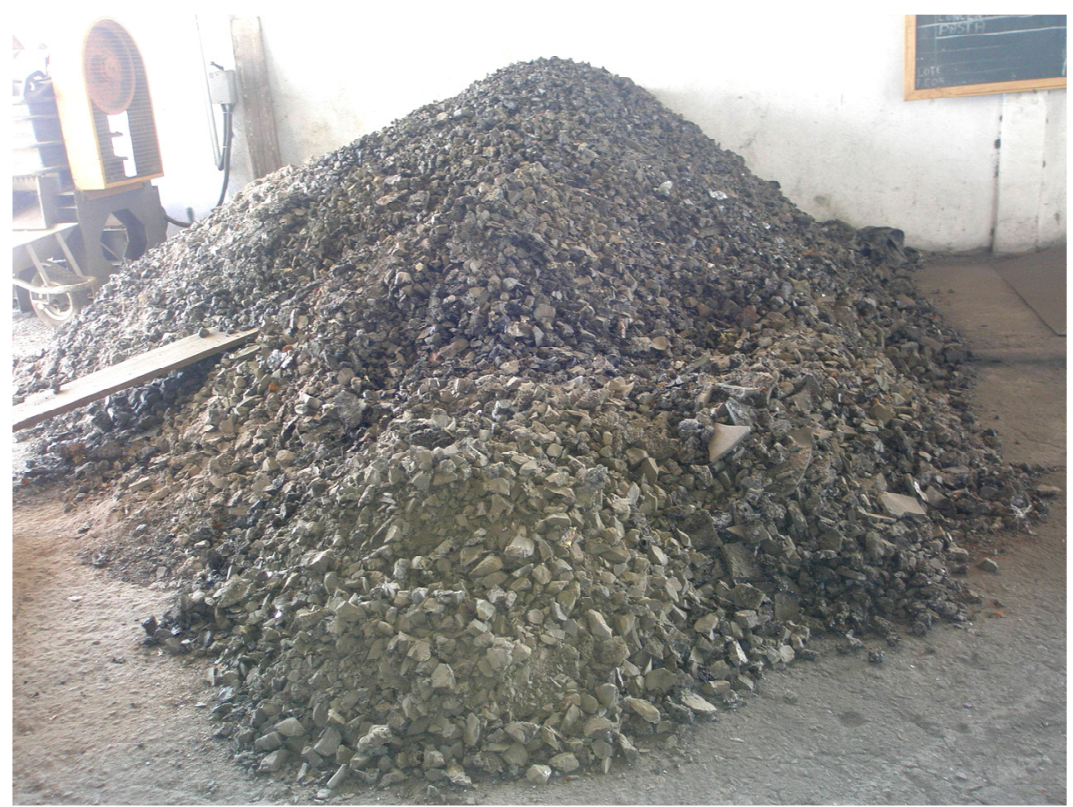

Figura 3. Cassiterita sendo preparada para ser levada ao forno. (Imagens: dos próprios autores)

\section{Beneficiamento da cassiterita $\left(\mathrm{SnO}_{2}\right)$}

A cassiterita é retirada do subsolo no garimpo Bom Futuro e chega à fundição com $66 \%$ de Sn puro, e com outros elementos como: ferro, cobre, bismuto, arsênio, chumbo, cadmio, antimônio e outros menos importantes. (HANAN, 1983).

$A \mathrm{SnO}_{2}$ é colocada no forno juntamente com carvão que ajuda na sua fundição. O forno é aquecido a alta temperatura e conta com ajuda de dois eletrodos de grafite. onde ocorre a seguinte reação química.

$$
\mathrm{SnO}_{2(\mathrm{~s})}+2 \mathrm{C}_{(\mathrm{s})} \rightarrow \mathrm{Sn}_{(\mathrm{l})}+2 \mathrm{CO}_{(\mathrm{g})}
$$

A cassiterita é colocada em sua forma sólida no forno (Figura 4), junto com o carvão, onde então, ocorre a reação e a cassiterita é transformada em estanho líquido e uma parte de óxido de carbono. 

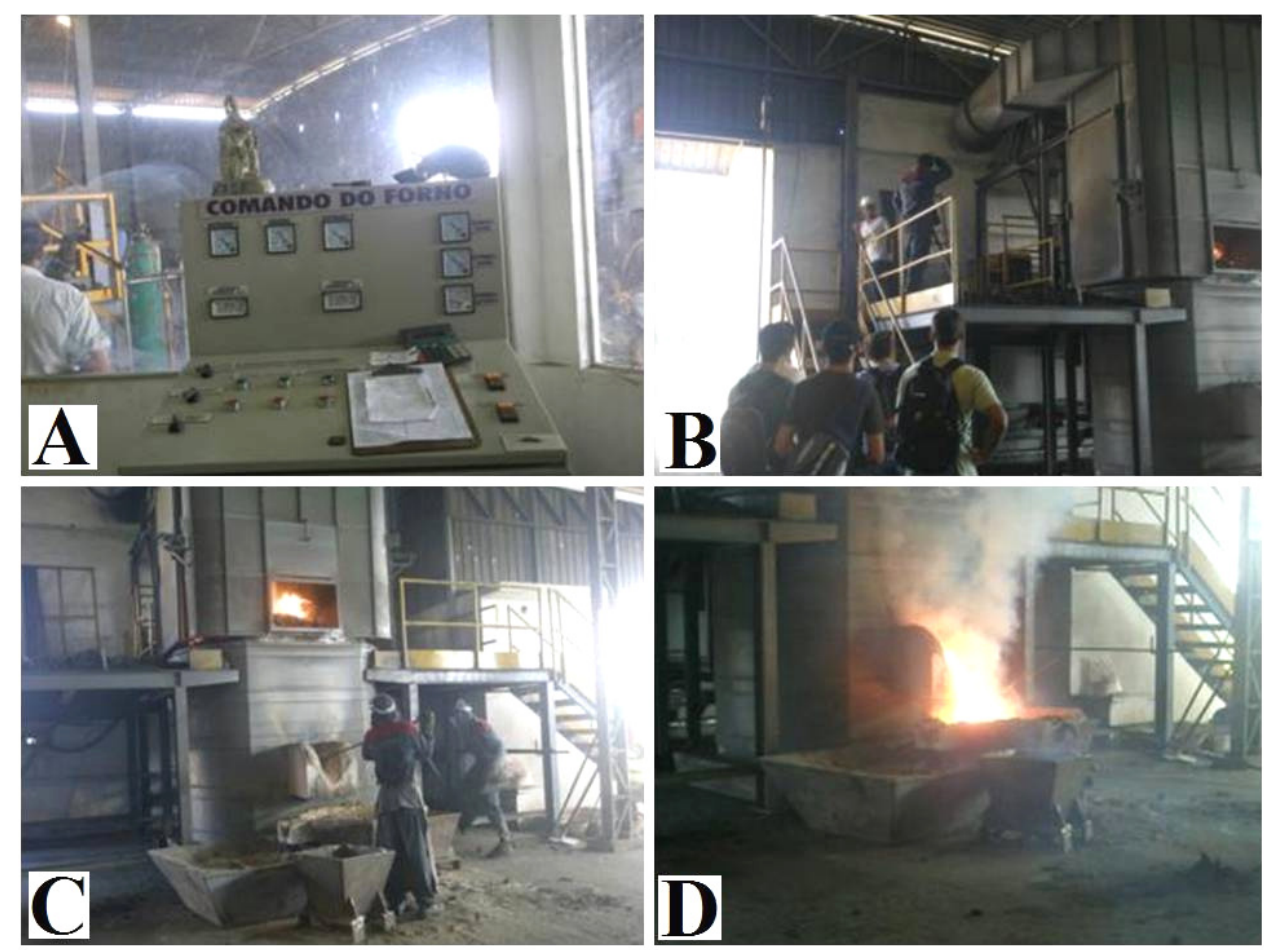

Figura 4. A) comando do forno de fundição; B) escada lateral de acesso aos fornos de fundição; C) forno de fundição; e D) estanho líquido sendo tirado do forno. (Imagens: dos próprios autores)

Estas substâncias liberadas através da fusão não podem ser soltas no ar, devido às mesmas poluírem o meio ambiente além de causar prejuízos a mineradora uma vez que a mesma leva consigo uma porcentagem alta de estanho.

Portanto, toda fumaça é capitada e levada através de dutos a um filtro, sendo filtrado o pó, esse que apresenta uma porção de $50 \%$ de estanho sendo novamente processado até seu completo aproveitamento.

Quando a cassiterita se encontra totalmente fundida é feita a sangria, processo onde a mesma é retirada do forno a uma temperatura de aproximadamente 1000 ㄷ C (Figura 4-D). É um processo cauteloso pelo perigo, uma vez que pode entupir a saída do forno. Caso isso ocorra, deve-se introduzir uma vara oca de ferro na boca do forno e aos poucos ir soltando oxigênio dentro do forno, isso leva ao desentupimento do mesmo. 

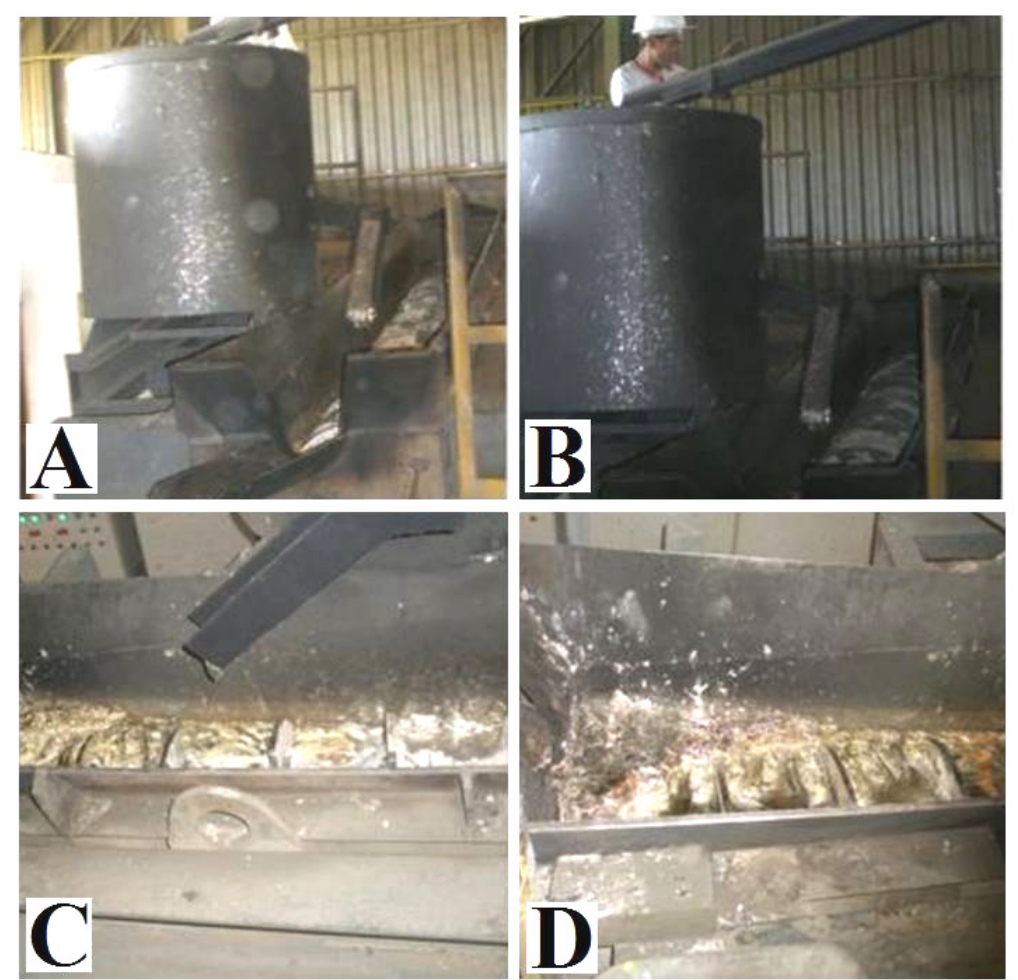

Figura 5. A, B panela de retirada cassiterita, C e D recristalizador (Imagens: dos próprios autores)

Ao sair do forno, as impurezas ou escórias ficam na parte superior por terem densidade menor que o estanho, podendo ser separada uma boa parte delas, porém nas impurezas ainda contém estanho, então posteriormente elas passam novamente pelo processo de fundição, onde com as escórias é utilizado o silício que age como redutor do ferro e o calcário que age como fundente da cassiterita.

Na segunda etapa do processo, o estanho ainda contém impurezas, que são retiradas no forno, sendo em seguida colocado em uma panela (Figura 5 A e B), onde é levado para um recristalizador (Figura 5 C e D) através de bombas, que fazem a separação por gravidade sendo essa a última fase.

As impurezas são mais pesadas que o estanho, sendo o Chumbo o mais pesado, ficando na região inferior onde vai atraindo todas as outras impurezas para ele, ficando o estanho com 99,98\% de pureza para a segunda parte do recristalizador, onde é jogada água para dar choque térmico e se transformar em cristais. Depois de se cristalizar, o estanho é fundido de novo para ser moldado em barras ou em formas que o cliente preferir como mostra a Figura 6, então está pronto para ser exportado. 

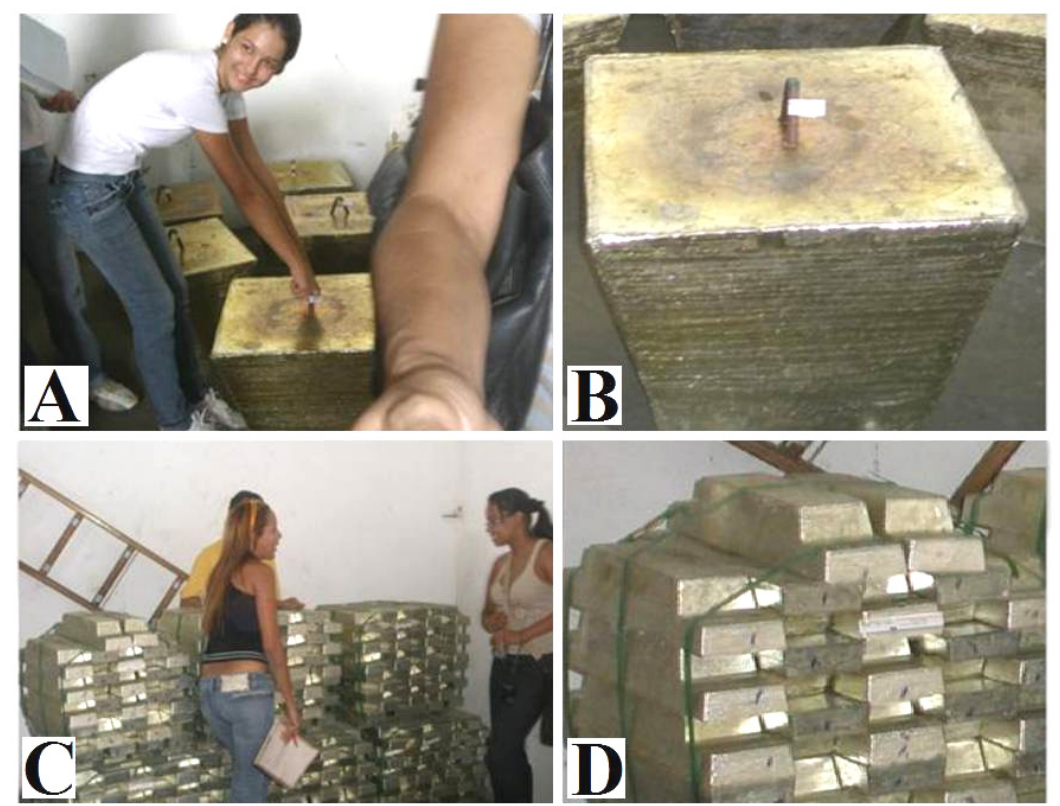

Figura 6. A, B, C e D barras de estanho de tamanhos e forma diferentes (Imagens: dos próprios autores)

\section{Estanho}

O stannum, etimologicamente do latim, é um elemento químico cujo símbolo é Sn pertence ao grupo 14 da tabela periódica. Suas propriedades químicas podem ser observadas na Tabela 1.

Tabela 1. Propriedades químicas do estanho.

\begin{tabular}{|c|c|}
\hline Número atômico & 50 \\
\hline Massa atômica & 118.098 \\
\hline Configuração eletrônica & $4 d^{10} 5 s^{2} 5 p^{2}$ \\
\hline Isótopos estáveis naturais & (\%)112Sn (0.95),114Sn (0.65), 115 Sn (0.34), \\
\hline Energias de ionização (kJ & 708.4; 1411.4; 2942; 3929.3 \\
\hline Eletronegatividade & $\begin{array}{l}\text { Snll 1.80(Pauling), 1.49(Sanderson) } \\
\text { SnIV 1.96(Pauling),1.72(Allred- Rochow), }\end{array}$ \\
\hline Densidade a $20 \circ \mathrm{C}\left(\mathrm{g} / \mathrm{cm}^{3}\right)$ & Forma $\beta: 7.265$ \\
\hline Estrutura & $\begin{array}{l}\text { Forma } \beta \text { (branca): tetragonal } \\
\text { Forma } \alpha \text { (cinza): cúbica, tipo diamante }\end{array}$ \\
\hline Ponto de fusão(ำ) & $232^{\circ}$ \\
\hline Ponto de ebulição(으) & $2623^{\circ}$ \\
\hline
\end{tabular}

Fonte: FILGUEIRAS, 1998 - adaptado pelos autores 
Classificado na categoria dos metais não-ferrosos, é sólido em condições ambientes de temperatura e pressão tem tendência em formar cátions (íons positivos) ao produzir substâncias simples ou compostas. O estado de oxidação do estanho pode ser bivalente $(+2)$ ou tetravalente $(+4)$, embora este último seja o mais encontrado. O estanho é o 48ㅇe elemento em ordem de abundância na Terra, ocorrendo na concentração média de 2.1 ppm. O estanho foi um dos primeiros metais a ser trabalhado pelo homem (CUTER, 2005).

Algumas características do estanho

- Bom condutor de calor e eletricidade.

- Dúctil, isto é, pode ser transformado em lâminas.

- Resistente a corrosão.

- Não é tóxico.

- Possui um brilho metálico característico.

\section{Principais usos do Estanho}

As aplicações industriais do estanho abrangem o revestimento de placas metálicas, atribuindo aos produtos finais propriedades antioxidantes e a formação de ligas com outros metais, para diversos usos, principalmente a fabricação de soldas. Os principais usos industriais do estanho são a fabricação de folha-de-flandres e de ligas metálicas como solda, bronze, ligas de pewter e em compostos químicos (RODRIGUES, 2001).

Folhas-de-flandres ainda são o principal campo de aplicação do estanho. Estima-se que cerca de $90 \%$ das folhas-de-flandres sejam destinadas às indústrias de embalagens como latas de cerveja, refrigerantes, óleos comestíveis e tintas, sendo utilizados de 4 a $4,5 \mathrm{~kg}$ de $\mathrm{Sn} / \mathrm{t}$ de folhade-flandres, respondendo por 30-40\% do consumo setorial de estanho (CUTER, 2005).

As propriedades como o baixo ponto de fusão e a afinidade em formar ligas com outros metais, dão ao estanho grande aplicabilidade na fabricação das soldas, que são compostos geralmente binários de estanho e outro metal, predominantemente o chumbo, podendo ter outros elementos traços associados, com larga aplicação nas indústrias eletroeletrônica e automobilística. As soldas são a segunda maior aplicação do estanho, respondendo por cerca de $28 \%$ do consumo aparente brasileiro (DNPM, 1994).

O bronze são ligas de Cu-Sn, que guardam uma proporção da ordem de 9:1. Caracterizamse por apresentarem boa resistência química e mecânica, sendo largamente empregados na construção de navios e indústria química. Não obstante, a liga Cu-Sn ser conhecida há vários séculos, ainda lhe é reservado um lugar de relativo destaque no consumo estanífero aparente mundial. No Brasil, esse segmento responde por cerca de $6 \%$ do total de Sn demandado (RODRIGUES, 2001).

Ligas de pewter são ligas compostas basicamente de estanho, antimônio e cobre que têm sido tradicionalmente usadas desde o Império Romano, na confecção de artigos de usos doméstico e eclesiástico como jarras, taças, castiçais etc (MACHADO, 1989). Parte desses itens são produzidos de chapas laminadas, que sofrem processos de estiramento, alisamento, repuxamento e usinamento. As estatísticas do DNPM, 1994 indicam que este segmento responde por cerca de $7 \%$ do consumo. 
A indústria química aplica o estanho em compostos inorgânicos, orgânicos e triorganoestânicos, para a produção de tintas, plásticos e fungicidas, destacando-se a vantagem de ser degradável, portanto não contamina o meio ambiente (RAMOS, 2003). O consumo do metal na indústria química vem se expandido progressivamente, estimando-se que já represente cerca de $15 \%$ da demanda mundial (HANAN, 1983).

\section{Análises laboratoriais}

No laboratório da mineradora são feitos três tipos de análises a fim de avaliar a qualidade do minério.

$\quad$ Análises de umidade;
$\quad \quad$ Análises de ferro;
$\quad \quad$ Análise via úmida;

As análises na cassiterita baseiam-se na Normativa Associação Brasileira de Normas Técnicas - ABNT - NBR 11567/2003, que determina o procedimento de análise que deve ser seguido pela empresa.

No laboratório da mineradora (Figura 7-A), recebe destaque o equipamento espectrofotômetro que é utilizado constantemente durante o processo de beneficiamento. Outro aparelho utilizado no laboratório é o de raios-X (Figura 7-C) que detecta quais elementos químicos existem nos minérios.

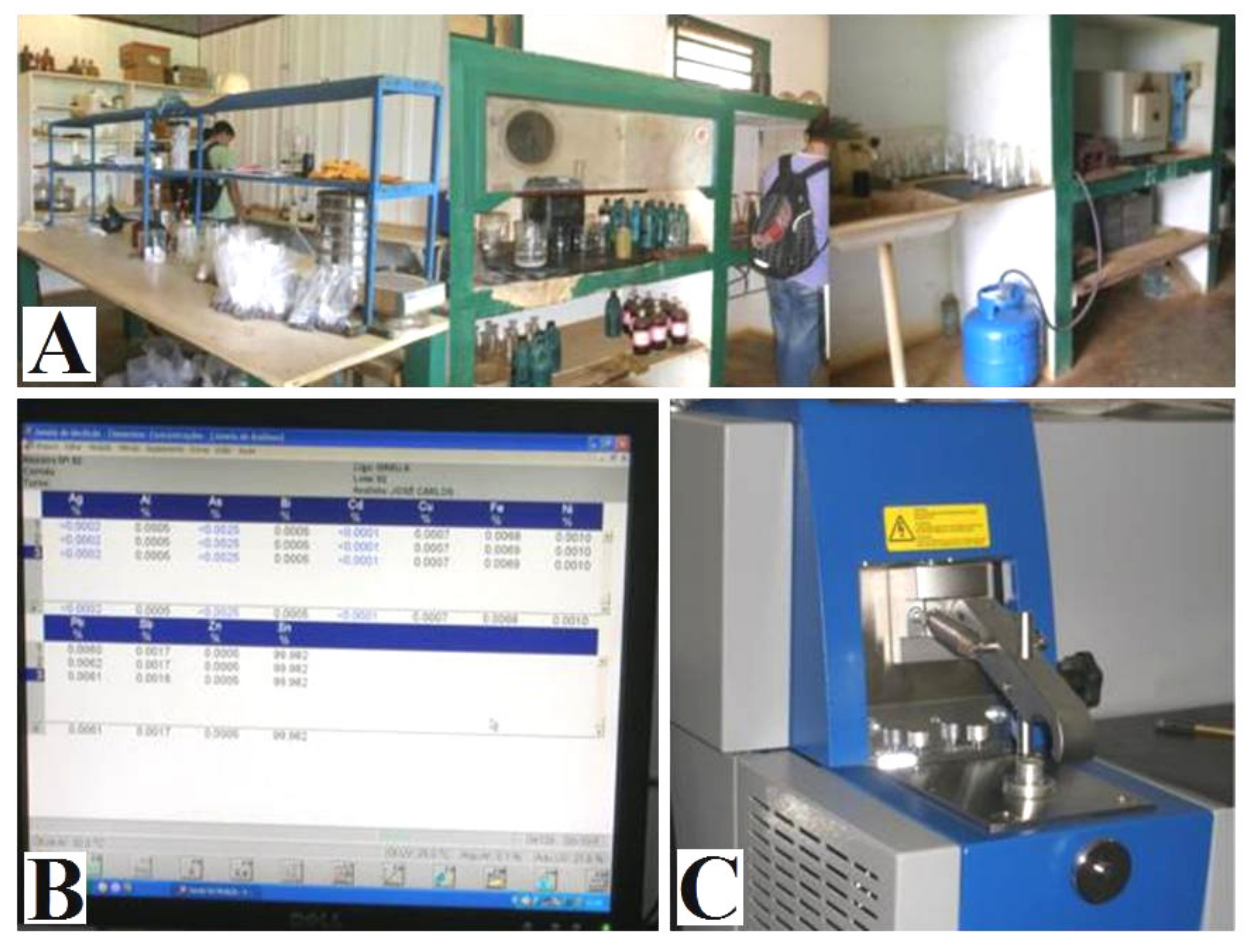

Figura 7. A- laboratório de análise, B- software do aparelho de raio-x e C- aparelho de raio-x (Imagens: dos próprios autores) 


\section{A visita ao Garimpo Bom Futuro}

Notoriamente observou-se que os acadêmicos apresentaram um grande interesse durante todas as etapas da visita, realizando registros, questionamentos, fotografando e explorando os assuntos de forma objetiva, ativa e dinâmica.

Todos os questionamentos gerados pelos acadêmicos durante o processo de visita eram sanados pelos funcionários responsáveis pelos respectivos setores da mineradora e o geólogo da empresa que acompanhou o grupo durante toda a visita. Os acadêmicos puderam distinguir claramente as diversas fases do processo de extração, os danos causados pela extração ao meio ambiente e o processamento da cassiterita, bem como as necessidades do laboratório de controle de qualidade.

Com essa visita, os alunos puderam relacionar as situações observadas e executadas na mineradora com a aprendizagem de química e da educação ambiental, promovendo integração dos estudos teóricos, além da grande importância da contextualização do conteúdo com o cotidiano de empresas e muitas vezes com o próprio dia a dia do acadêmico.

\section{CONSIDERAÇÕES FINAIS}

Observou-se que a Mineralogia está diretamente ligada com a Química, pois é através de processos químicos que a Cassiterita é beneficiada transformando-se em estanho para ser comercializado.

A Química também está presente em todos os minerais, nas suas fórmulas e características sendo importante a inclusão de uma visita ao garimpo como forma de interação do aluno ao meio extraclasse e da observação desses ambientes alternativos a sala de aula, e como a química está presente em vários lugares ao seu redor, bem como o garimpo pode ser uma ampla sala de aula para os mais variados conteúdos da educação ambiental e química.

A visita serviu como uma organizadora para o ensino de vários conceitos dos impactos ambientais e conceitos químicos e mostrou-se adequada por integrar as atividades extraclasses com a realidade dos alunos, proporcionou o conhecimento, por meio da descoberta e discussão, de alguns conceitos químicos e ambientais relacionados com a composição e etapas do processo de beneficiamento da cassiterita para a extração do estanho.

A aula desenvolveu o senso crítico dos alunos, contribuindo para o crescimento intelectual e formação de cidadãos mais conscientes, pois eles puderam vivenciar as implicações sociais e ambientais da extração da cassiterita, como a necessidade dos técnicos ambientais e do químico em uma empresa de extração. No decorrer da visita também ficou claro que a contextualização sugerida pelos novos Parâmetros Curriculares é um referencial metodológico e norteador do ensino eficaz para uma aprendizagem efetiva e significativa. 


\section{REFERÊNCIAS}

BRASIL. Parâmetros Curriculares Nacionais Ensino Médio + Orientações Educacionais Complementares aos Parâmetros Curriculares Nacionais: Ciências da Natureza, Matemática e suas Tecnologias. Ministério da Educação/Secretaria de Educação Básica, Brasília, DF, 2000. Disponível em: < http://portal.mec.gov.br/seb/arquivos/pdf/CienciasNatureza.pdf>. Acesso em: 24 abril 2011. BRASIL. Ministério de Minas e Energia. Mineração e Transformação Mineral-Sgm, Produto 18 Minério de Estanho, Relatório Técnico 27: perfil da mineração do Estanho. Secretaria de Geologia, 2009. BRASIL. Ministério de Minas e Energia. Departamento Nacional de Produção Mineral, Informe Mineral Desenvolvimento e Economia Mineral, 2004.

CHASSOT, A. I. Catalisando transformações na educação. Ijuí: UNIJUÍ, 1995.

CUTER, J. C. Formação e Evolução da Indústria de Estanho n Brasil. 2005.f.130, Monografia (Pós Graduados em Economia Política) - PUC SP, São Paulo, Universidade Católica de São Paulo, São Paulo, 2005. Disponível em: <http://www.sapientia.pucsp.br/tde_arquivos/10/TDE-2005-09-09T06:03:20Z 1172/Publico/Dissertacao.pdf> Acesso em: 27 nov. 2011.

DALL'IGNA LF. E o garimpo de cassiterita em Rondônia. Revista da CPRM,1996. 1: 56-61.

DARLENE, M. A. e SCHOBBENHAUS, C. Metalogênese do Brasil, (Distrito Bom Futuro), pag. 103, Editora Universidade de Brasília, Brasília, 2001.

DEPARTAMENTO NACIONAL DE PRODUÇÃO MINERAL (DNPM). Estanho.1994. Disponível em: <http://www.dprn.gov.br>. Acesso em: 2 fev. 2011.

FILGUEIRAS, C. A. L.. A nova química do estanho. Quím. Nova [online]. 1998, vol.21, n.2, pp. 176-192. ISSN 0100-4042.

HANAN, S.A. Panorama da Mineração e Metalurgia do Estanho no Brasil e no Mundo: subsídios para a elaboração da política setorial do país. Rio de Janeiro: SNIEE, 1983.

IBGE. Instituto Brasileiro de Geografia e Estatística. Banco de dados Cidades.2010. Disponível em:< http://www.ibge.gov.br/cidadesat/topwindow.htm?1>. Acesso em: 25/06/2011.

LONGO, R. M.; RIBEIRO, A. I. ; MELO, W. J. Caracterização física e química de áreas mineradas pela extração de cassiterita. Rev. Bragantia, v. 64, n.1, p. 101-107, 2005. Disponível em: <http://www.scielo.br/pdf/brag/v64n1/23857.pdf> Acesso em: 27 nov. 2011. MACHADO, I. F. Recursos minerais: política e sociedade. São Paulo: Edgard Blucher Ltda., 1989. PORSANI, J. L.; MENDONÇA, C. A.; BETTENCOURT, J. S.; HIODO, F. Y.; VIAN, J. A. J.; SILVA, J. E. Investigações GPR nos distritos mineiros de Santa Bárbara e Bom Futuro: Província Estanífera de Rondônia. Rev. Bras. Geof. , v. 22, n.1, p. 57-68, 2004. Disponível em: http://www.scielo.br/pdf/rbg/v22n1/a05v22n1.pdf>. Acesso em: 27 nov. 2011.

PREFEITURA. Municipal de Ariquemes. Localização de Ariquemes. 2011. Disponível em:< http://www.ariquemes.ro.gov.br/default.asp?secao=conteudo.asp\&tb=pt_ariquemes\&tit=Localização\&cp= localizacao>. Acesso em: 19/07/2011.

RAMOS, C. R. Estanho na Amazônia: o apogeu e ocaso da produção. Novos Cadernos NAEA, v. 6, n. 2, p. 3960, dez., 2003. Disponível em<http://www.periodicos.ufpa.br/index.php/ncn/article/view/87/138>. Acesso em: 27 nov. 2011.

RODRIGUES, A. F. S. Estanho, Bem Mineral, Balanço Mineral Brasileiro, 2001. Disponível em: <http://www.dnpm.gov.br/portal/assets/galeriaDocumento/BalancoMineral2001/estanho.pdf $>$. Acesso em: 27 nov. 2011.

RONALTTI, I. Uma perspectiva histórica e ambiental acerca dos garimpos de Rondônia. 2008. 